\title{
Phytochemical Analysis of Andrographis Paniculata and Catharanthus Rosea from Korba District, Chhattisgarh, India
}

\author{
Rajeshwari Prabha Lahare ${ }^{1}$, Anil Kumar Dashahre ${ }^{2}$, Yogesh Kumar Bisen ${ }^{3}$, Hari Shankar Yadav ${ }^{4 *}$
}

${ }^{1}$ Research scholar, Department of Biotechnology Govt Science College, Durg (CG), India

${ }^{2}$ National Tiger Conservation Authority Regional Office Ravinagar Nagpur Maharastra India

${ }^{3}$ Department of Biological Science, Rani Durgavati University Jabalpur (MP) India

${ }^{4}$ Uchh Madhyamik Shikshak, Govt. H.S. School Nikkum (Birsa) Balaghat (MP) India

DOI: $10.36347 / \mathrm{sajb} .2020 . \mathrm{v} 08 \mathrm{i12} .003$

| Received: 11.12 .2020 | Accepted: 24.12.2020 | Published: 29.12.2020

*Corresponding author: Dr. Hari Shankar Yadav

Abstract

Original Research Article

Andrographis paniculata and Catharanthus rosea are important ethno medicinal plant rich in bioactive compounds used in traditional Asian medicine for centuries. The plants contain rich source of bioactive compound having broad range of medicinal properties like antibacterial, antioxidant, anti-cancerous, anti-mutagenic, antifungal, anti- diabetic and antiviral activities. In the present study chloroform, methanol, petroleum ether and aqueous extracts were used for phytochemical test, TLC profiling, spectral analysis and antioxidant activity from leaf, stem and root parts of plants. Phytochemical analysis showed the presence of tannins, saponin, flavonoid, alkaloid, terpenoid, steroids, cardiac glycosides, quinones and gums in both plants. Methanol extract was used for TLC analysis for further identification of phytoconstituents in which we found maximum 5 bands in Andrographis paniculata with rf value (0.14 to 1.0) and Catharanthus rosea with rf value (0.22 to 1.0). Spectral analysis showed peak values for bioactive molecules. Highest antioxidant activity was found in aqueous and methanol extract which might be due to the presence of flavonoid and phenolic contents in both plants. This study should be beneficial for further characterization of bioactive compounds and identification of pharmaceutical lead compound.

Keywords: Andrographis paniculata, Catharanthus rosea, TLC, spectral analysis, antioxidant activity.

Copyright $\odot 2020$ The Author(s): This is an open-access article distributed under the terms of the Creative Commons Attribution 4.0 International License (CC BY-NC 4.0) which permits unrestricted use, distribution, and reproduction in any medium for non-commercial use provided the original author and source are credited.

\section{INTRODUCTION}

Herbal extract contain various phytocompounds or secondary metabolites that act against various diseases and their mode of action is different for each extract and compound respectively. In Asia and Europe whole parts of the plant are used in folk medicine. In India about 45000 plant species have known medicinal values which posses a variety of therapeutic properties. Andrographis paniculata and Catharanthus roseus are important medicinal plants used for treatment of various diseases due to its diverse pharmacological applications such as antibacterial, anti-diabetic, anti-allergic, antifungal, antioxidant and anti-cancer properties. Andrographis paniculata and Catharathus rosea are important medicinal plant used to cure various types of diseases. Andrographis paniculata popularly known as king of bitter is herbaceous, annual plant belongs to Acanthaceae family and distributed mostly in moist, shady areas with at a height of 30-110 $\mathrm{cm}$ and Catharathus rosea known as Vinca rosea is an evergreen sub herb plant belongs to Apocynaceae family. Both plants are rich in bioactive compounds and possess vast range of pharmacological properties.
Koteswara et al., [1] isolated and identified 30 flavonoids and labdane diterpenoids of Andrographis paniculata. Andrographolide a diterpene lactone isolated from Andrographis paniculata possess immunomodulatory properties. Anti-HIV and cytotoxic activity was reported from the six known compounds andrographolide, 12-didehydroandrographolide, 14-deoxyandrographolide, dimethoxyflavanone and 14-deoxy-11, andrograpanin, 5-hydroxy-7,85-hydroxy-7, 8-dimethoxyflavone isolated from the aerial parts of Andrographis paniculata [2]. Nanduri et al., [3] reported 8, 17-epoxy andrographolide showed cytotoxic activity. Tan et al. [4] reported that the major diterpenoid constituents of Andrographis paniculata showed cytotoxic property against human tumor cell lines. Catharanthus roseus contain a large group of alkaloids that have used in cancer treatment and it also contains flavonoid, saponin, alkaloid and carbohydrates. More than 100 monoterpenoidindole alkaloids (TIA) are produced by these plants in different organs. The ariel parts of the plant contain alkaloids like vindesine, vindeline tabersonine, vinblastine, vincristine, whereas 
raubasin, reserpine, catharanthine, vinceine, vineamine, and ajmalicine are present in basal or root parts of the plant. About 150 alkaloids of pharmacological importance are present on plant leaves. Nayak et al., [5] reported that ethanolic extract of Catharanthus roseus have wound healing property when treated to wounded rats and this property was due to increased tensile strength and hydroxyproline content of the granulation tissues. Antioxidant activity is evaluated mostly by DPPH method due to difference in free radical scavenging activity of different compounds the rate of reaction of DPPH differs in different compounds [6]. Oxidative stress arises due to imbalance between formation of reactive oxygen species and antioxidant defense system which may damage DNA, carbohydrate, proteins, and lipids [7]. Antioxidant is a defense mechanism that prevents the oxidation of other substances in low concentration the reactive oxygen species include hydroxyl radical, hydrogen peroxide, nitric oxide superoxide anion and per oxynitrite anion [8]. Andrographis paniculata and Catharanthus roseus are the most common plant used widely in traditional medicinal system. The phytocompounds present in plants are responsible for its biological activities like anticancer, antiviral, antibacterial, antioxidant, anti-hepatitis, anti-pyretic, anti-venom, anti-malarial, and antifungal activities. The aim of present study is to evaluate phytochemical analysis, TLC profiling, spectral analysis and antioxidant activity of Andrographis paniculata and Catharanthus roseus from Korba, Chhatisgarh, India.

\section{MATERIALS AND METHODS \\ Plant collection and identification}

Andrographis paniculata and Catharanthus roseus leaf, stem and root parts were collected from Korba district, Chhattisgarh, India. The plants were identified from Botanical Survey of India, Allahabad, India. The collected plant parts were washed; shade dried and grinned to make powder.

\section{Preparation of extracts}

$10 \mathrm{gms}$ of each powder was taken in $100 \mathrm{ml}$ of each solvent (methanol, chloroform, petroleum ether, aqueous) in soxhlet apparatus. Filtrates were used for screening of secondary metabolites by following the standard protocol.

\section{Phytochemical analysis}

Test for cardiac glycosides

$1 \mathrm{ml}$ of extract was taken and $0.5 \mathrm{~mL}$ glacial acetic acid was added then few drops of $3.5 \%$ ferric chloride solution were added and $1 \mathrm{~mL}$ of conc. Sulfuric acid was added slowly in the tube. A reddish brown ring was observed at the interface which indicates the presence of cardiac glycosides.
Test for terpenoid

$0.5 \mathrm{~mL}$ of plant extract was taken in a tube and $2 \mathrm{~mL}$ of chloroform was added then $3 \mathrm{~mL}$ of concentrated sulfuric acid was added, to form a lower layer. Occurrence of reddish brown colour at the interface indicates the presence of terpenoid.

\section{Test for steroids}

$0.5 \mathrm{~mL}$ of extract was dissolved in $3 \mathrm{ml}$ of chloroform then the solution was filtered, $2 \mathrm{~mL}$ of concentrated sulfuric acid was added to the filtrate a reddish brown color ring was observed in the interface which indicates the presence of steroid.

\section{Test for saponin}

$0.5 \mathrm{ml}$ of extract was taken in test tube then $5 \mathrm{~mL}$ of distilled water was added to it. The solution was vigorously shaken and stable persistent froth was observed for the presence of saponin.

\section{Test for tannins}

Take $0.5 \mathrm{~mL}$ of extract and $5 \mathrm{~mL}$ of distilled water in test tube then it was boiled and filtered then few drops of $1 \%$ ferric chloride were added. Deep green, brownish green or blue black coloration indicates the presence of tannin.

\section{Test for flavonoid}

$1 \mathrm{ml}$ of plant extract was taken in test tube and $3 \mathrm{ml}$ of ammonia solution was added in filtrate then concentrated sulfuric acid was added slowly. A yellow precipitation was observed which indicates the presence of flavonoid.

\section{Test for alkaloid}

$1 \mathrm{ml}$ of plant extract was taken in test tube and $1 \mathrm{ml}$ of glacial acetic acid was added and $2 \mathrm{ml}$ of methanol was added then add few drops of ammonia. Appearance of white precipitate indicates the presence of alkaloids.

Test for quinone

$1 \mathrm{ml}$ of plant extract was taken in test tube and $1 \mathrm{ml}$ of sodium hydroxide was added on it. Appearance of blue green or red color indicates the presence of quinones.

\section{Test for gum}

$0.5 \mathrm{ml}$ of extract was taken in test tube then $5 \mathrm{~mL}$ of distilled water was added to it. The solution was vigorously shaken formation of foam represents presence of gum.

\section{Thin layer chromatography}

Thin layer chromatography was performed in methanol leaf, stem and root extracts. Solvent system contains (Ethyl acetate: Methanol: Distill water in the ratio of (36:36:28).TLC plates were dried and bands were observed in UV- trans illuminator. The movement 
of the active compound was expressed by its retention factor $\left(R_{f}\right)$ values and were calculated for different samples.

\section{$\mathrm{R}_{\mathrm{f}}=$ Distance traveled by the solute Distance traveled by the solvent}

\section{Spectral analysis}

UV-Vis Spectrophotometer 119 was used to detect absorption maxima $(\lambda \max )$ for the presence of phytocompounds in crude extract of Catharanthus roseus and Andrographis paniculata within the range of 200 to $900 \mathrm{~nm}$ and was compared with the wavelength of standard compound.

\section{Antioxidant activity}

DPPH free radical scavenging activity was used for analysis of antioxidant activity in Andrographis paniculata and Catharanthus roseus. Methanol, chloroform, petroleum ether and aqueous extract of plants were examined by following the standard protocol of Koleva et al., [9]. DPPH solution of $0.3 \mathrm{mM}$ was prepared in methanol and kept in dark bottle to protect it from light. Control solution was prepared by dissolving $1 \mathrm{ml}$ of DPPH in $3 \mathrm{ml}$ of methanol solution. Test sample contain varying concentration $(0.2,0.4,0.6,0.8,1$ $\mathrm{mg} / \mathrm{ml}$ ) of different extracts and $1 \mathrm{ml}$ of DPPH was added and final volume of $4 \mathrm{ml}$ is makeup with methanol. The tubes were incubated in dark for 30 minutes and reading was taken at absorbance $517 \mathrm{~nm}$ in UV-Spectrophotometer. Ascorbic acid was taken as standard using methanol as diluents. The percentage inhibition by sample treatment is determined by the formula:

\section{$\%$ of inhibition of DPPH activity $=($ Absorbance of control - Absorbance of test sample $) \times 100$}

\section{Absorbance of control}

\section{RESULTS AND DISCUSSION \\ Phytochemical Analysis}

Secondary metabolites play major role in various pharmacological activities. In this study we have evaluated the phytochemical analysis, tlc profiling, spectral analysis and antioxidant activity of Andrographis paniculata and Catharanthus rosea. The screening of the phytochemical constituents of the plant from leaves, stem and roots of Catharanthus roseus and Andrographis paniculata was shown in (Table 1, 2, and 3 ). In the present study presence of alkaloid, tannins, saponin, steroids, cardiac glycoside, flavonoids, terpenoids, quinones, and gums were detected in Andrographis paniculata and Catharanthus rosea in varying concentration in all the extracts and showed potent biological activity and medicinal properties. In aqueous and methanol leaf extract saponin, tannin, terpenoids and flavonoids are present in all the three plants. Saponins are bitterness, insoluble in water and exhibit blood coagulating activity form foam in aqueous solution and possess hemolytic activity. Cardiac glycoside and alkaloids are present in all the plants. Quinones are present in aqueous extract of Andrographis paniculata. Gum is only found on chloroform extract of Andrographis paniculata. Flavonoids known as "nature's biological response modifiers" protect plant from pathogen attack. Flavonoids are polyphenolic compounds exhibit anti-ulcer, anti-hepatotoxic, anti-allergic, anti-viral, anti-cancer, anti-inflammatory activities. They are potent antioxidant capable of scavenging ROS due to presence of phenolic hydroxyl group [10]. Alkaloids, tannins and flavonoids showed medicinal activity against pathogens and are used in treatment of various diseases [11]. Saponins have antibiotic and hypercholesterolemia properties, steroids and terpenoids have analgesic activity, steroids and saponins have central nervous system properties. Tannin and flavonoids are responsible for anti-diarrheal activity [12].

Table-1: Showing phytochemical screening of leaf extracts of Andrographis paniculata and Catharanthus roseus

\begin{tabular}{|l|l|l|l|l|l|l|l|l|l|}
\hline \multirow{2}{*}{ Phytocompounds } & \multicolumn{2}{|l|}{ Petroleum Ether } & \multicolumn{2}{l|}{ Chloroform } & \multicolumn{2}{l|}{ Methanol } & \multicolumn{2}{l|}{ Aqueous } \\
\cline { 2 - 10 } & AP & CR & AP & CR & AP & CR & AP & CR \\
\hline Saponin & - & - & + & - & + & ++ & ++ & ++ \\
\hline Tannin & - & - & - & + & + & + & ++ & + \\
\hline Terpenoids & ++ & + & + & + & + & + & - & + \\
\hline Flavonoids & - & - & - & + & + & - & + & + \\
\hline Steroids & ++ & - & - & + & - & - & - & + \\
\hline Cardiac glycoside & - & - & + & - & + & - & - & - \\
\hline Alkaloids & - & + & - & - & + & + & + & + \\
\hline Quinones & - & - & - & - & - & - & + & - \\
\hline Gum & + & - & + & - & - & - & - & - \\
\hline
\end{tabular}


Table-2: Showing phytochemical screening of stem extracts of Andrographis paniculata and Catharanthus roseus

\begin{tabular}{|l|l|l|l|l|l|l|l|l|l|}
\hline \multirow{2}{*}{ Phytocompounds } & \multicolumn{2}{l|}{ Petroleum Ether } & \multicolumn{2}{c|}{ Chloroform } & \multicolumn{2}{c|}{ Methanol } & \multicolumn{2}{c|}{ Aqueous } \\
\cline { 2 - 11 } & AP & CR & AP & CR & AP & CR & AP & CR \\
\hline Saponin & + & - & ++ & - & - & + & - & ++ \\
\hline Tannin & + & - & - & + & - & + & ++ & - \\
\hline Terpenoids & + & + & ++ & - & + & + & - & - \\
\hline Flavonoids & - & + & - & + & - & + & ++ & + \\
\hline Steroids & + & - & ++ & - & ++ & + & - & - \\
\hline Cardiac glycoside & + & ++ & + & - & + & + & + & - \\
\hline Alkaloids & - & - & + & - & + & + & + & + \\
\hline Quinones & - & - & + & - & + & - & - & - \\
\hline Gum & + & - & - & - & - & - & - & - \\
\hline
\end{tabular}

Table-3: Showing phytochemical screening of root extracts of Andrographis paniculata and Catharanthus roseus

\begin{tabular}{|l|l|l|l|l|l|l|l|l|l|}
\hline \multirow{2}{*}{ Phytocompounds } & \multicolumn{2}{|c|}{ Petroleum Ether } & \multicolumn{2}{c|}{ Chloroform } & \multicolumn{2}{c|}{ Methanol } & \multicolumn{2}{c|}{ Aqueous } \\
\cline { 2 - 10 } & AP & CR & AP & CR & AP & CR & AP & CR \\
\hline Saponin & - & - & ++ & + & - & + & + & + \\
\hline Tannin & - & - & - & - & +++ & - & ++ & - \\
\hline Terpenoids & + & + & ++ & - & +++ & - & - & + \\
\hline Flavonoids & - & - & - & - & + & - & - & + \\
\hline Steroids & + & - & ++ & - & +++ & - & - & + \\
\hline Cardiac glycoside & - & + & ++ & + & ++ & - & + & + \\
\hline Alkaloids & - & - & - & - & - & - & - & + \\
\hline Quinones & - & - & - & - & + & - & + & - \\
\hline Gum & + & - & + & - & - & - & + & - \\
\hline
\end{tabular}

\section{TLC Analysis}

Thin layer chromatography was given in (Table-4) contains solvent system (ethyl acetate: methanol: distill water). The standard $\mathrm{Rf}$ value for vincristine was $0.39,0.74$ and for vinblastine was 0.49 and 0.77 in Andrographis paniculata standard andrographolide rf value was $0.31,0.17,0.54$ and 0.37 similarly in the present study the Rf value was found in leaf was $(0.16,0.56)$, stem $(0.14,0.54)$ and root $(0.15)$. Quercetin is a flavonoid and Rf value was $(0.68,0.73$, 0.76) which was also found in Andrographis paniculata. Catharathus rosea. Similar results was obtained in leaf methanol extract $(0.48)$, stem $(0.39,0.77)$ and root $(0.48$, $0.32,0.74)$ extract. This indicates presence of vincristine and vinblastine in the plant.

Table-4: TLC (Rf Value) for methanol leaf, stem and root extract of Andrographis paniculata and Catharanthus rosea

\begin{tabular}{|l|l|l|l|l|l|l|}
\hline \multirow{2}{*}{ Parts of plant } & \multicolumn{3}{|l|}{ Leaf } & \multicolumn{2}{l|}{ Stem } & Root \\
\cline { 2 - 7 } & AP & CR & AP & CR & AP & CR \\
\hline 1 & 0.16 & 0.25 & 0.14 & 0.22 & 0.15 & 0.32 \\
\hline 2 & 0.56 & 0.48 & 0.54 & 0.39 & 0.71 & 0.48 \\
\hline 3 & 0.67 & 0.53 & 0.67 & 0.69 & 0.78 & 0.74 \\
\hline 4 & 0.77 & 1.00 & 0.77 & 0.77 & 0.88 & 1.00 \\
\hline 5 & 1.00 & & 1.00 & 1.00 & 1.00 & \\
\hline
\end{tabular}

\section{UV-Spectral Analysis}

For further analysis UV-Vis Spectrophotometer119 was used to detect absorption maxima $(\lambda \max )$ for the presence of phyto compounds in crude methanol extract of Catharanthus roseus and Andrographis paniculata. In spectral analysis $\lambda$ max was scanned in the range of 200 to $900 \mathrm{~nm}$ for both plants (Fig 1, 2, 3, 4, 5 and 6). Andrographis paniculata showed peaks at 210nm, 229nm which might be due to presence of andrographolide. Gained et al., [13] and Pholphana et al., [14] reported UV-Spectrophotometer analysis of standard andrographolide was $220 \mathrm{~nm}$. Catharanthus roseus leaf methanol extract showed 3 peaks at $222 \mathrm{~nm}$, $298 \mathrm{~nm}$ and $266 \mathrm{~nm}$, stem showed peaks at value $214 \mathrm{~nm}$, $266 \mathrm{~nm}, 256 \mathrm{~nm}, 298 \mathrm{~nm}$ and in root 4 peaks were obtained in range of 200 to $340 \mathrm{~nm}$ and the peaks were $214 \mathrm{~nm}$ and 266nm, 256 and 298nm which might be due to the presence of vincristine and vinblastine. UV-absorbtion spectrum of Catharanthus roseus standard vincristine have three absorbtion peaks at $\lambda$ (max)- $(222,256,298)$ and vinblastine has two peaks at $\lambda$ $(\max )-(214,266)$ in methanol extract $[15,16]$. 


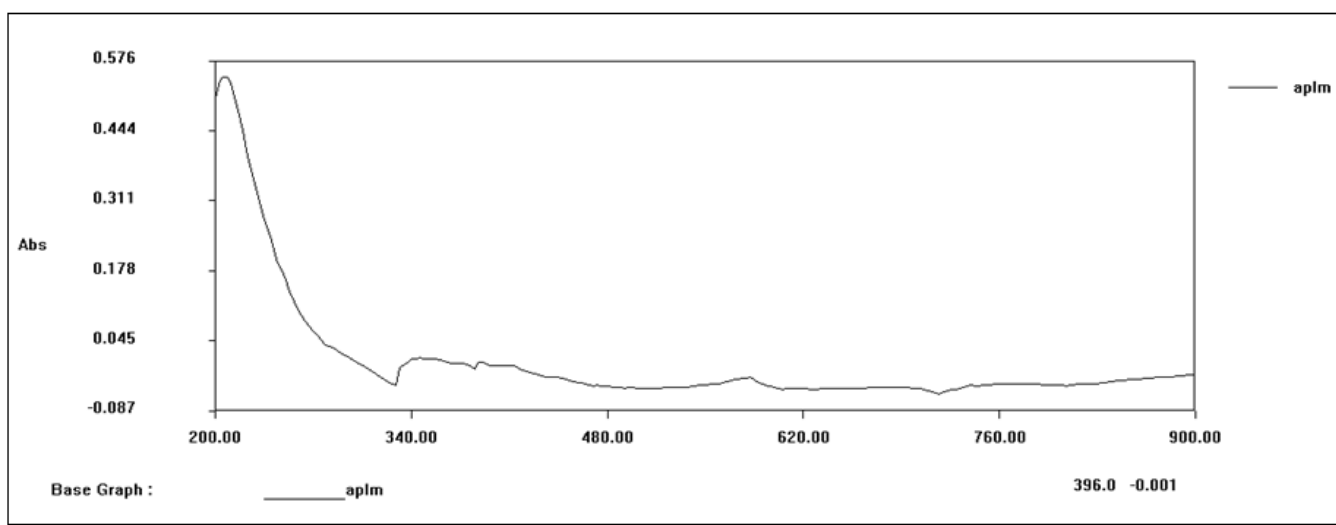

Fig-1: Showing UV-Vis Spectrophotometer analysis of leaf methanol extract of Andrographis paniculata

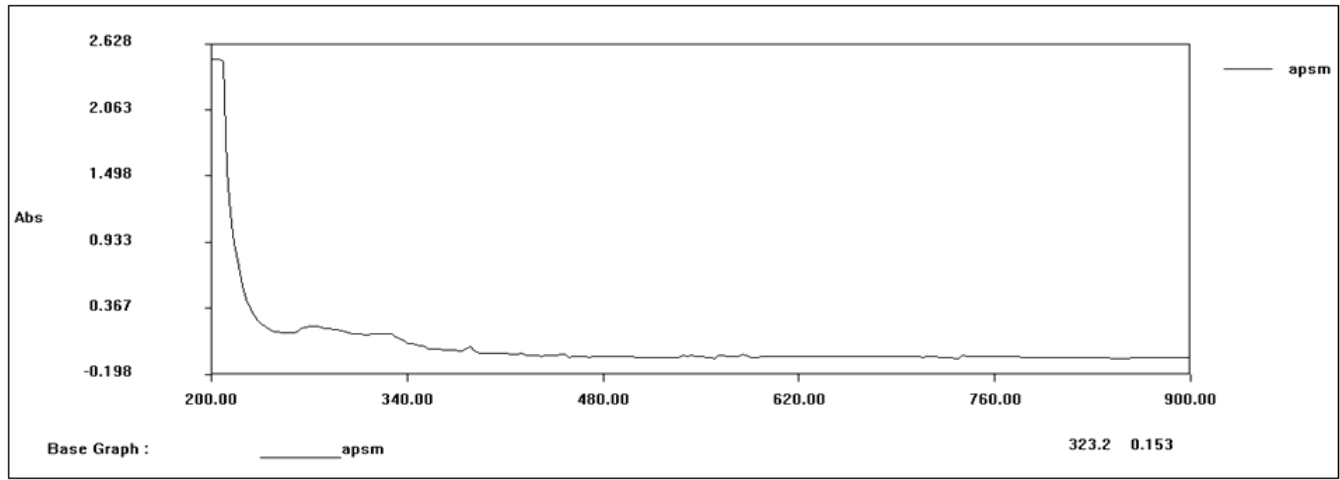

Fig-2: Showing UV-Vis Spectrophotometer analysis of stem methanol extract of Andrographis paniculata

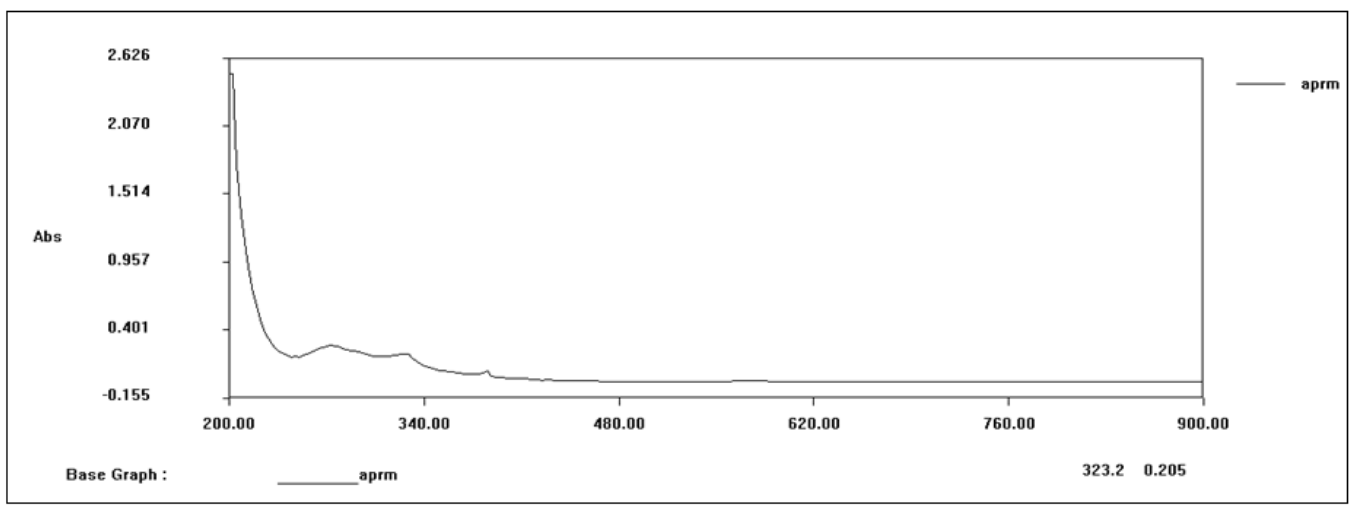

Fig-3: Showing UV-Vis Spectrophotometer analysis of root methanol extract of Andrographis paniculata

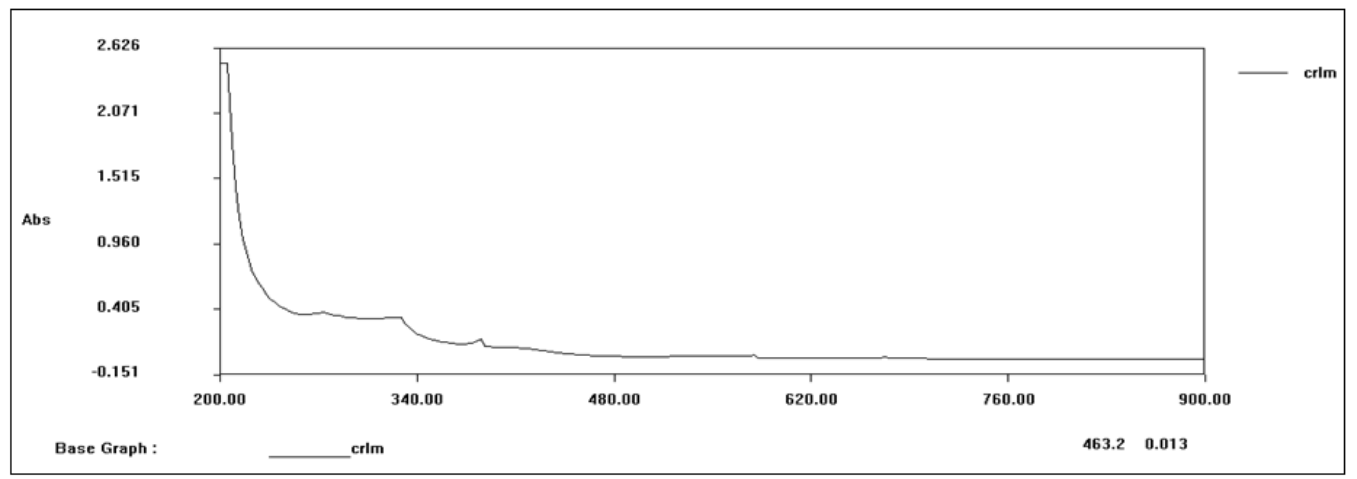

Fig-4: Showing UV-Vis Spectrophotometer analysis of leaf methanol extract of Catharanthus roseus 


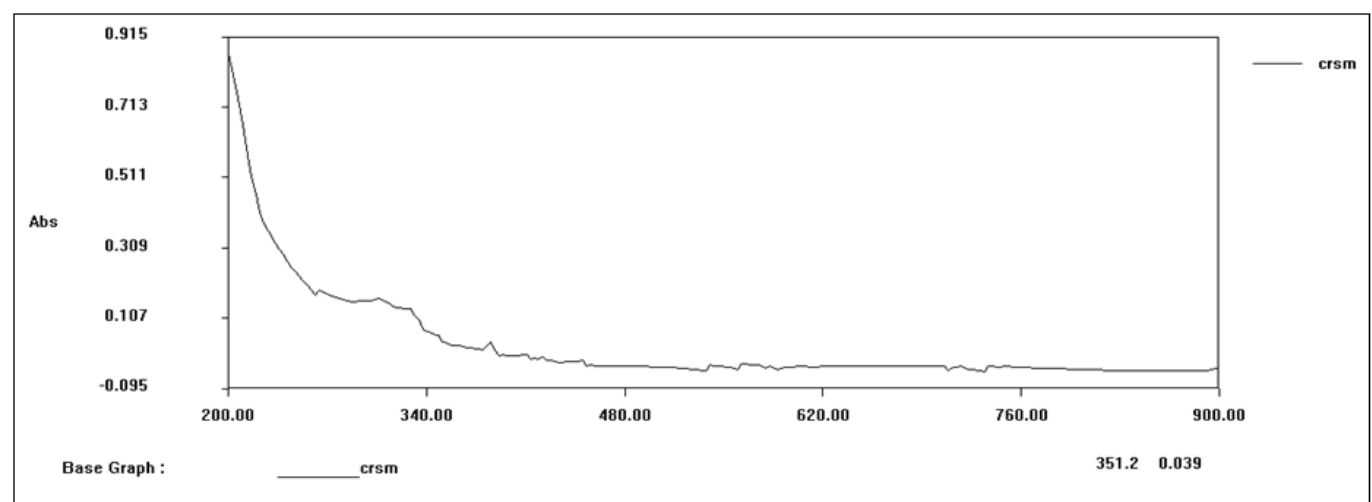

Fig-5: Showing UV-Vis Spectrophotometer analysis of stem methanol extract of Catharanthus roseus

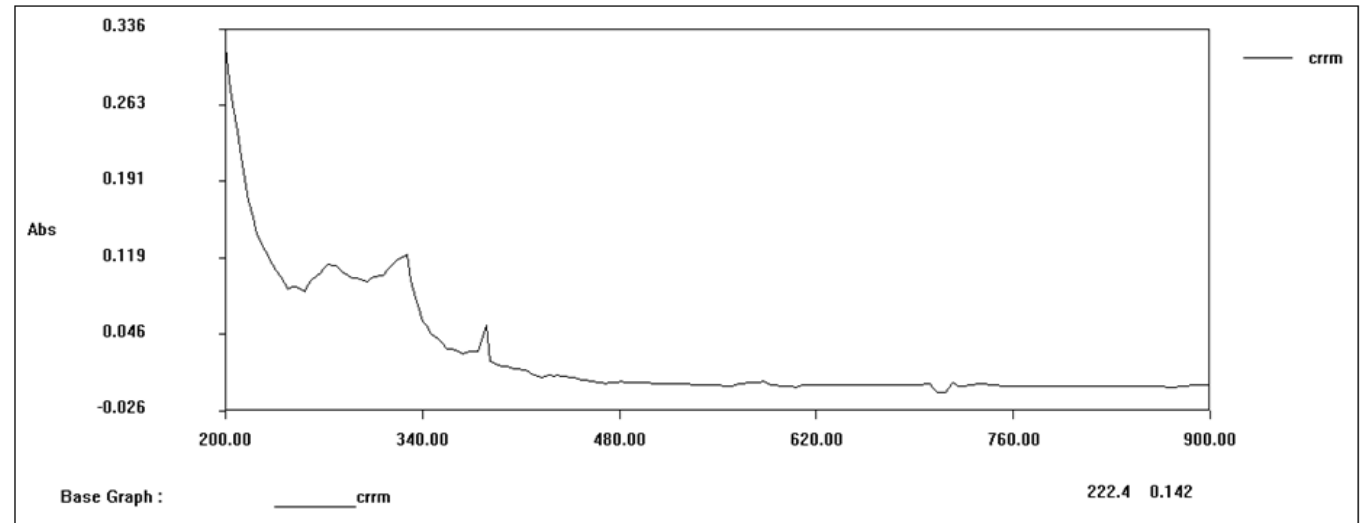

Fig-6: Showing UV-Vis Spectrophotometer analysis of root methanol extract of Catharanthus roseus

\section{Antioxidant Acitivity}

Andrographis paniculata and Catharathus rosea showed significant antioxidant activity in leaf, stem and root extracts (Fig 7, 8, 9, 10, 11 and 12). Pharmacological and clinical studies suggested that flavonoid exhibit radical scavenging activity against free radicals and acts effectively in inhibiting oxidation of lipoproteins and prevents various human diseases [17-19]. Plants showed good antioxidant activity due to the presence of flavonoid and phenolic compounds. DPPH method was used to analysis antioxidant activity of all the three plants and ascorbic acid was taken as standard and absorbance at $517 \mathrm{~nm}$. Absorbance decreases on increasing the concentration of test sample due to scavenging of free radicals by the hydroxyl groups of flavonoids in plant extract. Andrographis paniculata showed potent antioxidant activity in leaf aqueous and methanol extract, stem methanol and petroleum ether and in root methanol and aqueous extract. Catharanthus rosea showed antioxidant activity in leaf aqueous extract, stem petroleum ether and aqueous extract and root chloroform and methanol extract. Mensor et al., [20] reported that plant showed antioxidant activity due to the presence of flavonoids which contain free hydroxyl groups and can scavenge the free radicals more efficiently. Highest antioxidant activity was showed in aqueous extract in both plants due to the presence of flavonoid which scavenge free radicals efficiently.

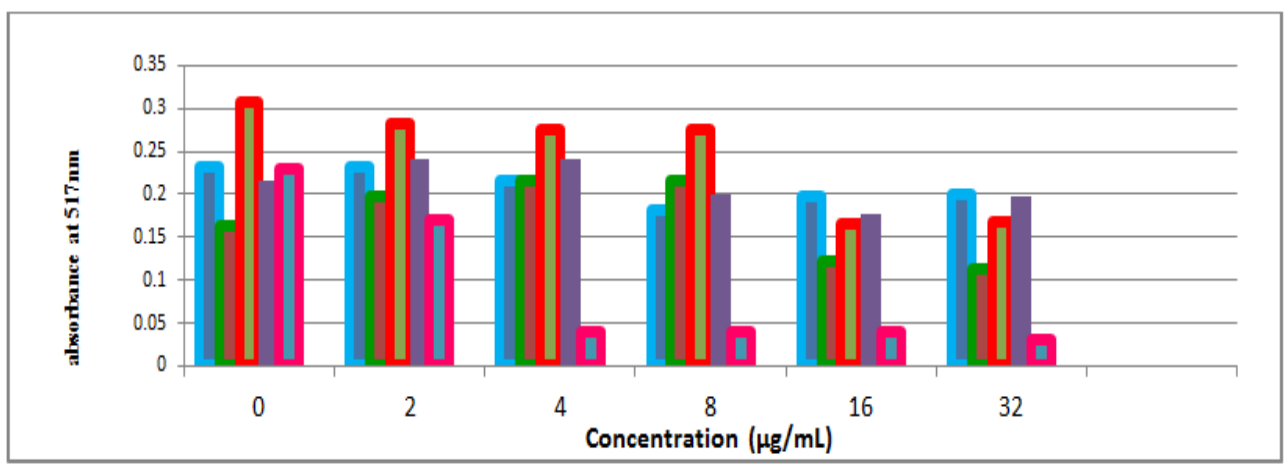

Fig-7: Showing absorbance for antioxidant activity of leaf extract of Andrographis paniculata by DPPH method 


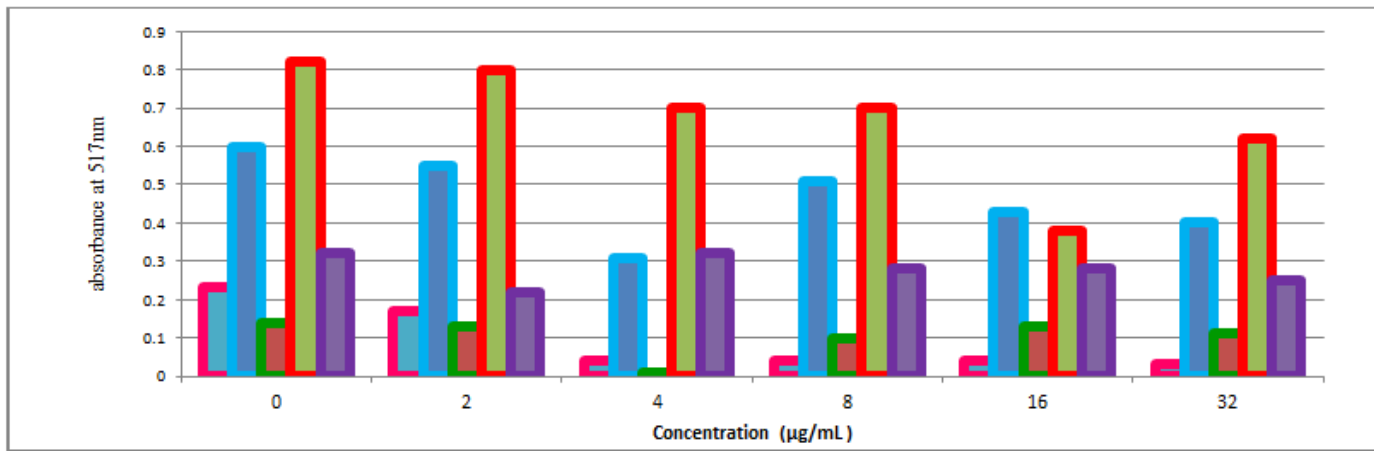

Fig-8: Showing absorbance for antioxidant activity of stem extract of Andrographis paniculata by DPPH method

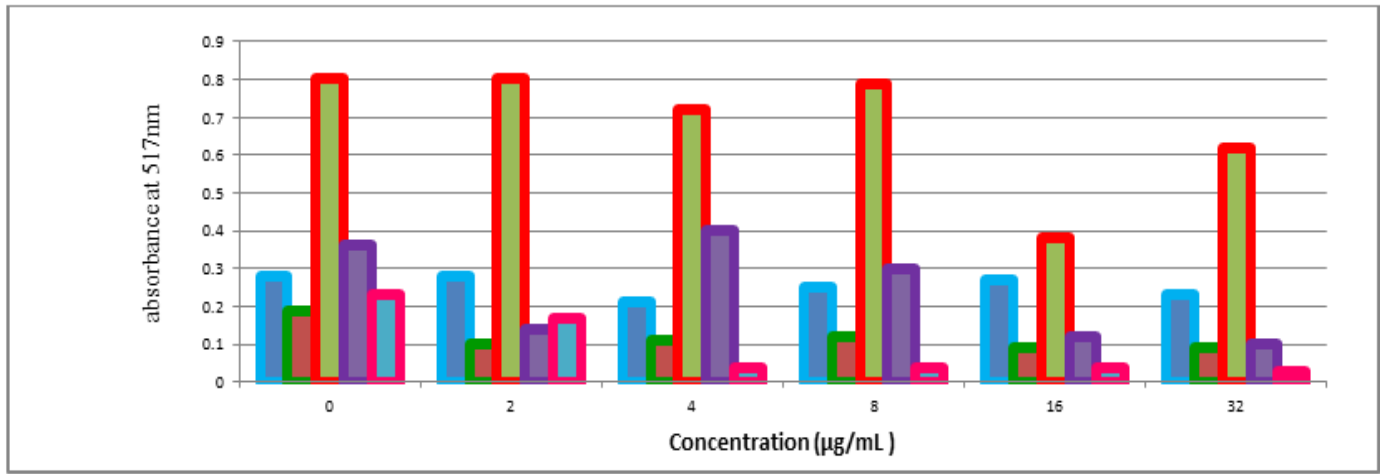

Fig-9: Showing absorbance for antioxidant activity of root extract of Andrographis paniculata by DPPH method

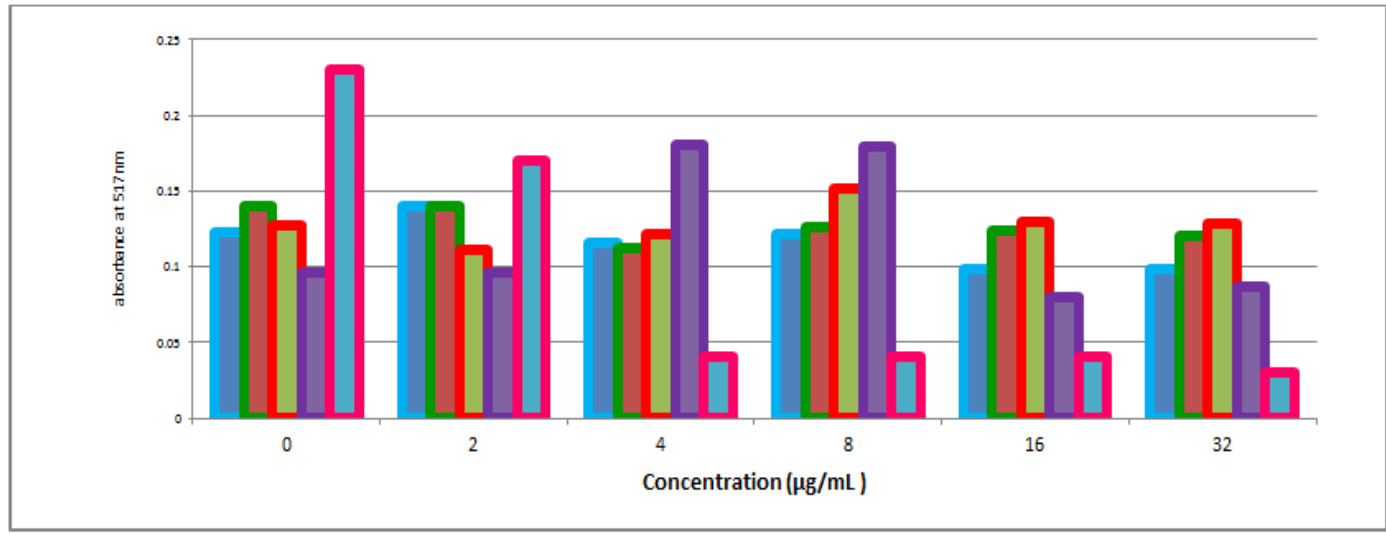

Fig-10: Showing absorbance for antioxidant activity of leaf extract of Catharanthus rosea by DPPH method

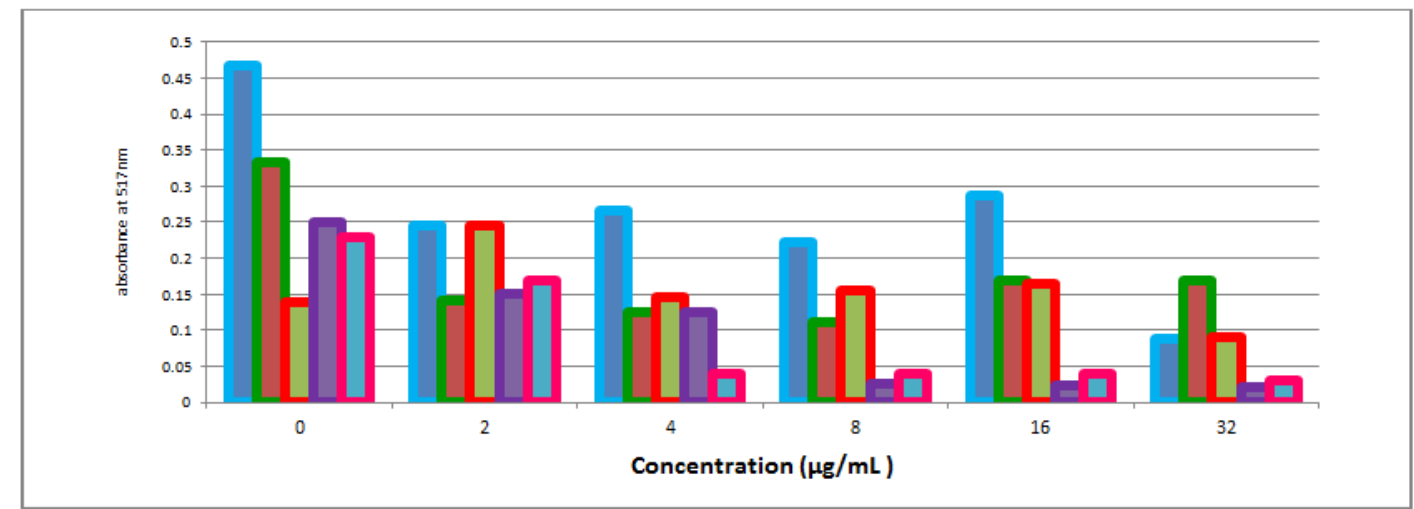

Fig-11: Showing absorbance for antioxidant activity of stem extract of Catharanthus rosea by DPPH method 


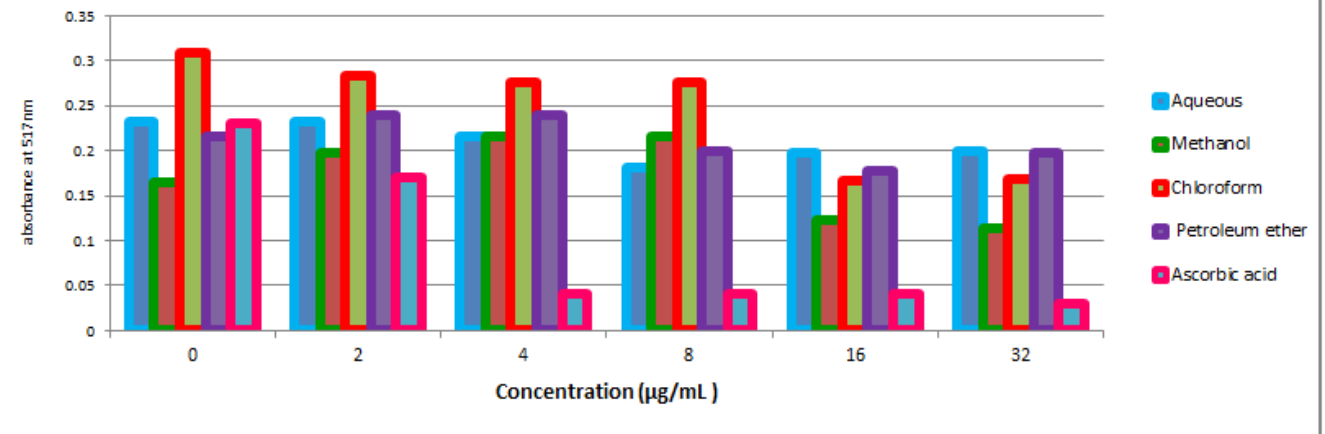

Fig-12: Showing absorbance for antioxidant activity of root extract of Catharanthus rosea by DPPH method

\section{CONCLUSION}

Plants are the reservoir of various chemical constituents and contain different biological and pharmacological properties that can be of valuable therapeutic index. Phytochemical constituents of the plant possess wide range of activities which provide protection against chronic and acute diseases. Phytochemical analysis showed rich contain of bioactive molecules in both plants due to the presence of steroid, terpenoid, flavonoid, tannin, cardiac glycoside, saponin, quinines, gum and alkaloids. Spectrophotometer showed peaks for bioactive molecules. Aqueous and methanol extract showed potent antioxidant activity followed by chloroform and petroleum ether. Further advanced studies have conducted on these medicinal plants for characterization and structure elucidation of bioactive molecules. This study should be beneficial in pharmacological as well as industrial point of view.

Conflict of interest: The authors declare no conflict of interests.

Acknowledgement: I would like to give thanks to UGC-RGNF fellowship for providing financial support.

\section{REFRENCES}

1. Rao YK, Vimalamma G, Rao CV, Tzeng YM. Flavonoids and andrographolides from Andrographis paniculata. Phytochemistry. 2004 Aug 1;65(16):2317-21.

2. Niranjan Reddy VL, Malla Reddy S, Ravikanth V, Krishnaiah P, Venkateshwar Goud T, Rao TP, Siva Ram T, Gonnade RG, Bhadbhade M, Venkateswarlu Y. A new bis-andrographolide ether from Andrographis paniculata nees and evaluation of anti-HIV activity. Natural Product Research. 2005 Apr 1;19(3):223-30.

3. Nanduri S, Nyavanandi VK, Thunuguntla SS, Kasu S, Pallerla MK, Ram PS, Rajagopal S, Kumar RA, Ramanujam R, Babu JM, Vyas K. Synthesis and structure-activity relationships of andrographolide analogues as novel cytotoxic agents. Bioorganic \& medicinal chemistry letters. 2004 Sep 20;14(18):4711-7.

4. Tan ML, Kuroyanagi M, Sulaiman SF, Najimudin $\mathrm{N}$, Muhammad TT. Cytotoxic activities of major diterpenoid constituents of Andrographis paniculata. In a panel of human tumor cell lines. Pharmaceutical biology. 2005 Jan 1;43(6):501-8.

5. Nayak BS, Anderson M, Pereira LP. Evaluation of wound-healing potential of Catharanthus roseus leaf extract in rats. Fitoterapia. 2007 Dec $1 ; 78(7-8): 540-4$.

6. Janaszewska A, Bartosz G. Assay of total antioxidant capacity: comparison of four methods as applied to human blood plasma. Scandinavian journal of clinical and laboratory investigation. 2002 Jan 1;62(3):231-6.

7. Halliwell BA, Gutteridge JM, Cross CE. Free radicals, antioxidants, and human disease: where are we now?. The Journal of laboratory and clinical medicine. 1992 Jun 1;119(6):598-620.

8. Nagendrappa G. An appreciation of free radical chemistry 3. Free radicals in diseases and health. Resonance. 2005 Apr 1;10(4):65-74.

9. Koleva II, Van Beek TA, Linssen JP, Groot AD, Evstatieva LN. Screening of plant extracts for antioxidant activity: a comparative study on three testing methods. Phytochemical Analysis: An International Journal of Plant Chemical and Biochemical Techniques. 2002 Jan;13(1):8-17.

10. Cao G, Sofic E, Prior RL. Antioxidant and prooxidant behavior of flavonoids: structure-activity relationships. Free radical biology and medicine. 1997 Jan 1;22(5):749-60.

11. Usman H, Osuji JC. Phytochemical and in vitro antimicrobial assay of the leaf extract of Newbouldia laevis. African Journal of Traditional, Complementary and Alternative Medicines. 2007;4(4):476-80.

12. Enzo AP. Traditional plants and herbal remedies used in the treatment of diarrheal diseases. Mode of action, quality, efficacy and safety considerations. In: Ahmad I, Aqul F, Qwaiss M, Modern Phytomedicine Turning Medicinal Plants indo 
Drugs. WILEY-VCH Verlag GMBH \& Co. KGQA. Weinheim, 2007; 248-260.

13. Gaind KN, Dar RN, Kaul RN. Spectrophotometric estimation of andrographolide in Kalmegh. Indian Journal of Pharmacy. 1963;25:225-6.

14. Pholphana N, Rangkadilok N, Thongnest S, Ruchirawat S, Ruchirawat M, Satayavivad J. Determination and variation of three active diterpenoids in Andrographis paniculata (Burm. f.) Nees. Phytochemical Analysis: An International Journal of Plant Chemical and Biochemical Techniques. 2004 Nov;15(6):365-71.

15. British Pharmacopoeia, Her Majesty's Stationary Office, London. Vol. I-II. Monographs: electronic version; 2013.

16. Sander GW. Quantitative analysis of metabolic pathways in Catharanthus roseus hairy roots metabolically engineered for terpenoid indole alkaloid overproduction. 2009.
17. Ames BN, Shigenaga MK, Hagen TM. Oxidants, antioxidants, and the degenerative diseases of aging. Proceedings of the National Academy of Sciences. 1993 Sep 1;90(17):7915-22.

18. Heinonen IM, Meyer AS, Frankel EN. Antioxidant activity of berry phenolics on human low-density lipoprotein and liposome oxidation. Journal of Agricultural and Food Chemistry. 1998 Oct 19;46(10):4107-12.

19. Rice-Evans CA, Miller NJ. Antioxidant activities of flavonoids as bioactive components of food. Biochemical Society Transactions. 1996 Aug 1;24(3):790-5.

20. Mensor LL, Menezes FS, Leitão GG, Reis AS, Santos TC, Coube CS, Leitão SG. Screening of Brazilian plant extracts for antioxidant activity by the use of DPPH free radical method. Phytotherapy research. 2001 Mar;15(2):127-30. 